\title{
O DISCURSO EDUCACIONAL E O ALMANAQUE DO BIOTÔNICO FONTOURA: POR ENTRE PRÁTICAS DE LEITURA E A PRODUÇÃO DE UMA REPRESENTAÇÃO DO SERTANEJO (1920-1950)
}

\author{
Marcelo Oliano Machado \\ Ednéia Regina Rossi \\ Fátima Maria Neves \\ Universidade Estadual de Maringá - UEM
}

\section{RESUMO}

Neste artigo, tecemos relações entre as representações do homem do campo, veiculadas pelo Almanaque do Biotônico Fontoura, e a produção de uma memória coletiva acerca do sertanejo. O Almanaque foi usado nas escolas como material de leitura e circulou em diferentes espaços públicos e privados. Sua leitura contribuiu para consolidar uma imagem de atraso e indolência do sertanejo.

Palavras-chave: Almanaque do Biotônico Fontoura; História da Educação, representação do sertanejo; Brasil (1920-1950).

\section{THE EDUCATIONAL DISCOURSE AND THE BIOTONICO FONTOURA ALMANAC: BETWEEN READING PRACTICES AND THE PRODUCTION OF A BACKCOUNTRY MAN'S REPRESENTATION (1920-1950)}

\begin{abstract}
This article explores the relationship between the backcountry man, as portrayed by Biotonico Fontoura Almanac, and the production of a collective memory about the backcountry person. This Almanac was used in schools as reading material and it circulated in different public and private areas. Its reading helped to consolidate an image of backwardness and indolence of the backcountry man.

Keywords: Biotonico Fontoura Almanac; History of Education; Backcountry man's Representation; Brazil (1920-1950).
\end{abstract}

Com uma estética persuasiva e utilizando um discurso atrelado ao ideário educacional e higiênico propagado por intelectuais do Brasil do início do século XX, o Laboratório Fontoura, na década de 1920, criou seu meio de divulgação: o Almanaque do Biotônico Fontoura. Com uma média de 40 páginas, ele trazia informações acerca de saúde e higiene, além de fazer propaganda dos produtos do laboratório, como, por exemplo, o elixir Biotônico Fontoura. Entre seus colaboradores, Monteiro Lobato se destacou, pois foi o responsável pela publicação da história do Jeca Tatu, a qual se tornou uma das maiores peças publicitárias do Brasil. De acordo com Park (1999), ela atravessou quase um século, atingindo uma tiragem superior a 100 milhões de exemplares na sua última edição, em 1982, um número astronômico se comparado aos 50 mil da primeira edição em 1920. 
É importante lembrar que, na década de 1920, florescia, no país, um pensamento científico e também político que pode ter contribuído para efetivar a criação do Almanaque. Cientistas das mais diversas áreas começaram a defender o argumento de que não seria a raça que determinaria o atraso ou o desenvolvimento de uma nação, mas as condições de saúde da população. Este pensamento se colocava num contexto em que, como afirma Stepan (1976), cidades, como a do Rio de Janeiro, por exemplo, encontravam-se mergulhadas em problemas tão graves de saúde pública que impediam a sua própria administração. Vejamos os dados:

Uma população que já ultrapassava 600.000 habitantes estava confinada, às vezes, em casas anti-higiênicas, muitas situadas em ruas não pavimentadas e com esgotos a céu aberto. Não só a febre amarela, a peste e a varíola eram grandes assassinas, mas o sarampo, a escarlatina, a influenza, e as doenças intestinais menos dramáticas, mas sempre presentes, e a tuberculose cobravam seu tributo anual em vidas humanas. (STEPAN, 1976, p. 85).

Diante desses dados alarmantes, proliferaram, em todo território nacional, uma série de debates em torno da questão, na tentativa de encontrar possíveis projetos e propostas que resultassem em soluções rápidas, lógicas e positivas para o problema. É importante lembrar que, no centro dessas discussões, não se envolveram apenas médicos e cientistas da saúde, mas profissionais e pesquisadores de diferentes áreas do conhecimento fizeram parte desses debates que, aos poucos, foi adquirindo proporções de movimento nacional em prol da higienização e saneamento do país.

Schraiber (1989), refletindo sobre esse momento, aponta para a importância atribuída à regeneração de todos os corpos, independente da condição social. Para ele:
A importância da manutenção e da recuperação do corpo não é apresentada como particular por referência às classes sociais, mas como geral para o conjunto de sociedade; expressa, assim, não interesses particulares, mas o interesse geral da nação, visto que na dissolução das classes sociais em um conjunto homogêneo de cidadãos iguais - a nação - os interesses de uma classe são apresentados como os interesses de todos. (SCHRAIBER, 1989, p. 71).

Ao aproximar este debate da criação e divulgação do Almanaque Fontoura, podese interpretar que essas produções vieram ao encontro do que governos e cientistas ambicionavam, ou seja, a criação de um programa de medicina social planejado e que tivesse, também, uma continuidade no combate às mazelas nacionais. Além da descoberta de como medicalizar a sociedade brasileira, obedecendo a uma ordem de igualdade e homogeneidade, para a possível eficácia no controle das epidemias e no desenvolvimento da higienização. Foi então que, baseados nos estudos do cientista Oswaldo Cruz, os intelectuais adeptos da perspectiva higienista encontraram um modelo supostamente mais apropriado para dar início às ações medicamentosas; seria o que se de denominou de campanhismo, que predominou entre os anos de 1918 e 1924.

O higienísmo constitui-se num forte movimento, ao longo do século XIX e início do século XX, de orientação positivista. Foi formado por médicos que buscavam impor-se aos centros de decisão do Estado para obter investimentos e intervir não só na regulamentação daquilo que estaria relacionado especificamente à área de saúde, mas também no ordenamento 
de muitas outras esferas da vida social. Diante dos altos índices de mortalidade infantil e das precárias condições de saúde dos adultos, e tendo em vista a disseminação de novos conhecimentos e técnicas provenientes do avanço da ciência, o higienismo conseguiu influenciar decisivamente a emergência de novas concepções e novos hábitos. (MERISSE et al., 1987, p. 33-34).

Considerando os estudos de Merisse et al. (1987), é possível interpretar que havia uma clara predisposição por parte desses cientistas em pensar e agir sobre a saúde do brasileiro. Em termos práticos, esse movimento começou pelas cidades (em especial Rio de Janeiro e São Paulo), nas quais a urgência era maior devido à alta concentração de pessoas e para assegurar o progresso e o avanço industrial.

Para intelectuais como Cruz Costa (1904-1978) e Monteiro Lobato (1882-1948), o sertão, embora portador de grande riqueza e sustentabilidade, não era valorizado por projetos políticos e sociais, ocasionando o não desenvolvimento de suas gentes nos mais variados aspectos da vida humana.

O sertão fizera, no alvorecer na República, a sua dramática aparição no cenário da vida brasileira, revelando aspectos trágicos de nossa formação. [...] Ascendemos, de choque, arrebatados no caudal dos ideais modernos, deixando na penumbra secular em que jazem, no âmago do País, um terço de nossa gente. (COSTA, 1967, p. 354).

As necessidades fundamentais de higienização e saúde do campo levaram à publicação, em 1917, do Código Sanitário Rural, visando à transformação do sertanejo e prevendo mudanças importantes na demografia do campo. Do ponto de vista de uma literatura sobre saúde, doenças e práticas de cura no Brasil, pode-se verificar que o consumo de elixires foi, a princípio, uma alternativa na busca de uma solução para o problema. Caracterizado como medicina popular, muitas vezes com a interpretação de práticas e ideias rudes e equivocadas, o consumo desses medicamentos teve seus fundamentos arraigados na imitação do modelo europeu de exercício da medicina e sua funcionalidade era a cura de doenças típicas da falta de saneamento, como, por exemplo, a anemia, os vermes e a desnutrição.

Neste contexto, Monteiro Lobato e Cândido Fontoura começaram a abordar com maior ênfase o sanitarismo rural. Lobato, que outrora culpara o sertanejo por sua pobreza, caracterizando-o como indolente e inapto para o trabalho (ver o artigo "Velha Praga", 1914, publicado no jornal O Estado de São Paulo), passa a atribuir às más condições de saúde, sobretudo a do caipira paulista, a responsabilidade pelas mazelas sociais. Podemos interpretar que este universo intelectual de explicação do problema social brasileiro teria criado as condições favoráveis para a união Lobato \& Fontoura, dando ao Almanaque do Biotônico Fontoura um formato característico de peça publicitária.

Enquanto peça publicitária, certas práticas de leitura podem mobilizar alterações de hábitos culturais e, aos poucos, transformarem um estilo de vida. Não é por acaso que os textos publicitários, preferencialmente aqueles direcionados a grandes parcelas da população, objetivam guiar seus leitores para a aquisição de outro comportamento. "A publicidade serve mais para promover o consumo como um modo de vida do que para anunciar produtos." (ADLER; FIRESTONE, 2003, p. 29).

Adler e Firestone (2003) buscam demonstrar que a finalidade dos textos publicitários é controlar e condicionar os sujeitos. No entanto, nem sempre a intenção do autor corresponde aos usos feitos por seus leitores; nas práticas de leituras, o discurso 
publicitário pode encontrar-se envolto de novas e velhas práticas. Parafraseando Chartier (1994, p. 102), lê-se muito e de forma diferente também a publicidade.

Partindo do princípio de que a criação desse impresso ocorreu em um momento histórico que possuía a convicção de que a reforma da sociedade se efetivaria mediante a reforma do próprio homem, as associações discursivas encontradas no Almanaque são instrumentos decisivos na propagação dessa mentalidade.

O destaque dessa época, e talvez a peça de propaganda que tenha ficado mais conhecida no Brasil, é o Almanaque Fontoura, criado por Lobato e tendo como protagonista sua personagem emblemática, o Jeca Tatu. O Almanaque tinha como finalidade primeira promover a marca do elixir fortificante Biotônico Fontoura, e era distribuído em todo o território nacional. A compra de um frasco do elixir dava direito a um exemplar do almanaque, com suas histórias de cunho desenvolvimentista, característico de Lobato. Apresentava um discurso claro de convite a mudanças de procedimentos, de melhoria de atitudes em busca de mais conforto e saúde. (DIAS, 2006, p. 222).

Uma combinação de ingredientes publicitários, educacionais e literários que juntos trilharam o ambiente rural nacional, assegurados por aportes teóricos de intelectuais que estavam interessados no crescimento da nação em suas esferas progressistas. O Almanaque foi dosado de ideais educacionais capazes de se sobrepor ao produto que estava encarregado de divulgar, o elixir Biotônico Fontoura.

Não desconsiderando a incidência dos inúmeros outros discursos que circularam Brasil afora em torno da importância do desenvolvimento educacional para o progresso da nação, tomaremos como exemplo o adotado por Monteiro Lobato ao escrever a história do Jeca Tatu.

Parte-se do entendimento de que à tentativa de, na primeira metade do século XX, fixar o sertanejo no campo por meio do processo educacional, denominado pela historiografia da educação de "ruralismo pedagógico", "movimento que defendia uma escola integrada às condições locais regionalistas, cujo objetivo maior era promover a fixação do homem ao campo" (LEITE, 2002, p. 28), vincularam-se intenções de uma disciplinarização de seus hábitos e costumes, mediante a educação ligada à higiene, ao trabalho e modo de vida.

Primeiramente é preciso duvidar de representações que atribuem ao homem do campo uma indiferença em relação ao desejo pela educação, estudos evidenciam o interesse do sertanejo pela escola antes mesmo da sua criação em áreas que habitavam (PARK, 1999; ROSSI, 2003). Segundo dados do IBGE, naquele momento, quase $80 \%$ da população residia na zona rural, o número de escolas rurais existentes não atendia a demanda desses sujeitos que viviam distantes das cidades e centros urbanos. Muitas foram as estratégias desenvolvidas por eles para sua inserção no mundo letrado, ao mesmo tempo em que outras estratégias foram pensadas por educadores e intelectuais que intencionavam, por meio da educação, disciplinar hábitos e costumes desses sujeitos. É neste contexto de intenções que o Almanaque será situado na história da educação, integrando-o como um importante objeto de estudos para os pesquisadores deste campo.

Em 1918, ao publicar a primeira edição de O Problema Vital, reunindo uma série de 14 artigos veiculados pelo jornal $O$ Estado de São Paulo, Monteiro Lobato, ao afirmar, no epílogo da edição, que "O Jeca não é assim, o Jeca está assim", poderia não imaginar que alguns anos depois este personagem se tornaria um ícone da cultura brasileira e grande aliado dos propósitos educacionais do início do século XX. Assim, 
No discurso cívico da ABEi, a figura de um brasileiro doente e indolente, apático e degenerado, alegoriza os males do país. Transformar essa espécie de Jeca Tatu em brasileiro laborioso e disciplinado, saudável e produtivo era o que se esperava da escola. (CARVALHO, 2003, p. 48).

É possível afirmar que o Almanaque do Biotônico Fontoura tornou-se um importante meio de implementação dos novos fins tomados pela educação no Brasil daquela época. Em um período em que as ideias nacionalistas se consolidavam e a migração e imigração aumentava a cada dia, o discurso educacional, não obstante, passava a ser visto como o esteio para a uniformização dos valores e sentimentos nacionais, inclusive, no que se referia à modernização, ciência e indústria, ao progresso.

Embalada nessa onda progressista, a educação, como afirmou Carvalho (2003), passou a ser uma espécie de chave que possibilitaria à nação ir do pesadelo de um país atrasado ao sonho de tornar-se civilizado. Nesse contexto, vários dispositivos foram criados com o intuito de ordenar e regular a vida cotidiana das pessoas que se enquadravam no perfil de brasileiro atrasado e indolente. O Almanaque do Biotônico Fontoura foi um desses dispositivos, afinal:

O progresso era o outro nome do espírito científico, de que o almanaque recebe também alguns respingos. Uma mentalidade científica generalizadora faz aparecer aí a importância do desenvolvimento científico. (...) Por outro lado, no almanaque, forja se uma idéia de ciência, do papel que ela tem e deve desempenhar na marcha da sociedade industrial. (NOVA, 1996, p. 138-139).

Há evidencias, inclusive, de que essa característica do Almanaque Fontoura em forjar uma ideia de ciência possa ter contribuído para que ele adentrasse nas escolas, visto que era uma prática da cultura escolar a realização de palestras que abordavam, de forma racional e científica, assuntos relacionados à saúde e à instrução de novos hábitos higiênicos. Alguns depoimentos de sujeitos que vivenciaram essa prática fazem referências a essas palestras e à distribuição do Almanaque após sua realização.

Quando eu estava no segundo ano da Escola de Aparecido Bonito, que fica em Santa Fé do Sul, houve uma epidemia de amarelão. A prefeitura fez um programa de prevenção, principalmente nas escolas rurais. Como a maioria das crianças andava descalço, eram barrigudos, fracos e com vermes, uma senhora da cidade que era "metida" a médica, examinava os olhos, boca e ouvido das crianças, distribuindo um vidro de Biotônico para cada criança, por mês. Quando os médicos foram na escola chamaram os pais para dar uma palestra sobre a doença. Distribuíram o Biotônico e o livrinho. A partir daí, na minha casa, sempre se consultava este livrinho para tudo. O único irmão que lia, lia para nós todos. (PARK, 1998, p.103).

Assim, ao ter sua primeira edição circulando no Brasil a partir de 1920, o Almanaque, além de trazer um slogan que direcionava a população para a propaganda de um Tônico capaz de impulsionar o desenvolvimento escolar das crianças: $B e a B A, B e$ é Bé, Be i Bi, o tônico Fontoura, veiculava a história da personagem Jeca Tatu de Monteiro Lobato que, após consumir o medicamento, passou da condição de pobre, indolente e analfabeto para rico, trabalhador e inteligente. Não demorou muito e o livreto, que era 
distribuído gratuitamente nas farmácias, passou a ocupar espaço importante nas casas dos brasileiros, especialmente na daqueles que viviam no campo, assumindo não apenas um papel importante no aprendizado de novos hábitos de higienização do corpo, mas como instrumento fundamental na alfabetização e letramento dos sujeitos. Assim afirma um leitor do Almanaque, nascido em 1916:

\begin{abstract}
A primeira vez que vi um armanaque foi no orfanato. Acho que era 1928. Eles mostrava pras crianças, prá num anda discarça. O que era de mais interesse era a história do Jeca Tatu. A professora aproveitava... La se usava os remédio indicado nele. No orfanato tinha o livro sagrado e o armanaque. A professora ensinava a chave. Eu quero dizê, as letra. Elas acaba sendo a chave, sem elas ocê num entra. Num lê. Ai eu procurava as letra no armanaque (PARK, 1998, p. 142).
\end{abstract}

Pouco a pouco a história do Jeca foi se alastrando pelo país e o Almanaque tornando-se um material atrativo para todas as idades. Por meio da fala do depoente, é possível afirmar que o Almanaque Fontoura assumiu, em alguns locais, o papel de material propriamente escolar, utilizado para o ensino das primeiras letras. A utilização de almanaques como material de leitura pelas escolas, especialmente as do campo, foi evidenciada nos estudos de Park (1998, p. 145), que afirmou: "[...] pelo almanaque a roça se aproxima da biblioteca". No caso do Almanaque Fontoura, é possível identificar que sua utilização recebia um incentivo extra, uma vez que, pela história do Jeca, as crianças e seus familiares encontravam informações medicamentosas e de higiene que iam ao encontro do ideal de higienização do período.

O uso do Almanaque na escola e em outros espaços levou o Jeca a tornar-se conhecido em praticamente todo o Brasil. Como representante caricatural do caboclo brasileiro, sobretudo daquele residente no interior paulista, a história dessa personagem trazia lições de higiene, de trabalho e, especialmente, de mudanças de hábitos e costumes, enfocadas como a "chave mágica" que conduziria a boas e novas condições de vida aquele que a elas se lançassem. Afinal, o entendimento de que gente da roça não carecia de estudos, cedia lugar a outro discurso que voltava suas intenções para o homem do campo.

Se a educação na Primeira República foi voltada quase que exclusivamente aos imigrantes como recurso civilizatório (CARVALHO, 2003), foi no final da primeira e início da Segunda República que o Brasil "despertou para a educação rural." (LEITE, 2002, p. 28).

Por um lado, se cidades como Rio de Janeiro e São Paulo incitavam, no início do século XX, perspectivas de desenvolvimento baseadas na hegemonia cultural das fábricas. Isto é, o operário precisava estar preparado para atuar em suas funções nos moldes da ciência, da técnica e, consequentemente, do progresso. Por outro, essa espécie de "prelúdio republicano", como chamou Sevcenko (1998), precisava chegar ao campo. Nesta perspectiva, o sertanejo deveria ser preparado para atuar no ambiente rural e, aos poucos, ser inserido no ideal de progresso republicano. Aos olhos de progressistas como Monteiro Lobato, isso seria alcançado mediante a educação do homem do campo. Esses sujeitos, a maioria analfabetos, não teriam condições de acompanhar o crescimento do país caso permanecessem nesta condição. Assim, propagou-se a mentalidade de que a leitura seria um elo importante entre o homem e o progresso.

Lobato não tardou a perceber a importância de sua literatura de entretenimento para a educação das crianças. Ele próprio levou seus livros para as escolas. Como publicista, crítico social, ele sabia 
naturalmente que fazia o trabalho de um "educador de adultos"... Nem sempre suave, está certo, mas sempre admiravelmente claro, irrepreensivelmente didático. E inventivo, fantasioso, atraente. (NUNES, 1986, p. 87).

É possível perceber a influência da literatura na configuração de um imaginário coletivo, a veiculação sucessiva de imagens cria e ou transforma as representações. Embora o Almanaque Fontoura, que trazia em cores atraentes a imagem do Jeca Tatu de pobre e indolente no início da narrativa para rico e inteligente no final dela, pudesse proporcionar ao leitor daquele momento outra interpretação de sertanejo não foi o que se verificou na prática.

Neste cenário de possíveis transformações, a representação do homem do campo estava atrelada, ainda, a ambiguidades. Por um lado, permanecia a imagem de sertanejo romântico identificado nas obras de José de Alencar (1829-1877), que o descrevia como um sujeito ingênuo e primitivo; e, por outro lado, a imagem difundida em obras como a de Monteiro Lobato (1882-1948), como no artigo Urupês (publicado pela primeira vez em 1914, no jornal O Estado de São Paulo) que o relacionava à visão de sujeira, doença e atraso social. Essas narrativas, tanto de Lobato como de Alencar, foram representações distintas de sertanejo e que, durante décadas, permaneceram no imaginário coletivo. Os dois conceitos de sertanejo circularam entre os intelectuais, ora dividindo-os, ora contribuindo para a formação de um pensamento que os levará a defender determinadas políticas de educação e de saneamento para o Brasil. A falta de saneamento era entendida como causa de males, como o fracasso escolar e o baixo desenvolvimento social, em virtude das doenças por ele provocadas.

$\mathrm{Na}$ grande campanha de saneamento, o Almanaque do Biotônico Fontoura teve um papel importante. Com linguagem escrita de fácil entendimento, repleto de imagens coloridas que falavam por si, os exemplares desse folheto traziam o Jeca Tatuzinho, personagem de Monteiro Lobato, como exemplo de prosperidade a ser seguida. Aos poucos, o Jeca tornou-se uma das mais conhecidas personagens da cultura brasileira, adquirindo um conceito caricatural de sertanejo. Não obstante seu próprio contexto de criação, passou por uma série de metamorfoses: de caboclo preguiçoso, parasita funesto da terra, indolente, vítima de doenças para a de fazendeiro bem-sucedido.

É possível afirmar que o Almanaque propagou novos comportamentos higiênicos e de saúde, contudo, ao representar o sertanejo como "desnutrido, barrigudo e pobre" contribuiu para criar uma imagem do sertanejo a partir do Jeca Tatuzinho. Assim diz uma leitora:

Eram folhetos ilustrados com a imagem do Jeca Tatu cagando no matinho, a barriga inchada de vermes, o amarelão, a inércia. Na minha cabeça de menina, a idéia cresceu assim: nunca ser como o Jeca Tatu. Depois, já vivendo em São Paulo, a figura do Jeca confirmou-se na derivação cômica dela: Mazzaropi. Só muito mais tarde me surpreendi ao descobrir que o interior paulista, de onde vinham Jeca Tatu e Mazzaropi, era outra coisa. Mas essa passagem, a transformação do Jeca Tatu em novo rico, não ficaria bem elaborada na minha cabeça. (PARK, 1998, p. 91).

A princípio, o que se destaca na memória da leitora é a primeira versão caricatural do Jeca, enquanto pobre e doente. Pode-se observar que o Almanaque do Biotônico Fontoura, como um material de leitura, propiciou a sujeitos de poder aquisitivo e de 
acesso cultural diferenciados a produção de sentidos imprevisíveis, sendo que seus efeitos não puderam ser controlados.

Essa afirmação torna-se mais consistente quando considerada a perspectiva teórica de Chartier (1999), que pensa a leitura como prática inventiva, resultado não de uma, mas de várias maneiras de ler. Desse modo, o simples fato de pegar um livro e manuseá-lo já torna a prática da leitura algo particular com características peculiares, o próprio uso do livro é uma variante individual.

Uma vez escrito e saído das prensas, o livro, seja ele qual for, está suscetível a uma multiplicidade de usos. Ele é feito para ser lido, claro, mas as modalidades do ler são, elas próprias, múltiplas, diferentes segundo as épocas, os lugares, os ambientes [...] a leitura não é uma invariante histórica - mesmo nas suas modalidades mais físicas -, mas um gesto, individual ou coletivo, dependente das formas de sociabilidade, das representações do saber ou do lazer, das concepções da individualidade. (CHARTIER, 2004, p. 173).

Ao ler, cada indivíduo busca um significado para aquilo que lê, faz relações internas com seus conhecimentos, cria expectativas, busca finalidades. Mesmo feita de modo silencioso e solitário, a leitura não deixa de ser um processo dinâmico. Como afirma Chartier (1994, p. 17), “[...] os autores não escrevem livros: não, eles escrevem textos que se tornam objetos escritos, manuscritos, gravados, impressos e, hoje, informatizados". Ao que parece, é o leitor que presa a construção dos significados daquilo que lê chegando, às vezes, a desconstruir as ideias originais do autor.

Assim, o Almanaque do Biotônico Fontoura, além de representar seu laboratório, tornou-se material de leitura de adultos e crianças, ensinando a eles noções de higiene e saúde, como andarem limpos, asseados, calçados, além de trabalharem para uma vida feliz e próspera. Pode-se dizer que a disposição ou aceitação da personagem Jeca Tatuzinho em aprender outra forma para viver, de incorporar outros cuidados de higiene e saúde intencionou produzir, em seus leitores, o desejo de outro modelo e padrão de vida. Jeca Tatuzinho tornou-se um modelo a ser seguido. Todos que se encontrassem naquelas condições poderiam vir a superá-las, desde que incorporassem uma forma de vida apoiada nos conhecimentos científicos, como ele incorporou.

Contudo, no movimento desta intenção civilizatória, propagou-se ou se reforçou uma imagem do homem do campo no imaginário coletivo. Sobre as formas de representação de campo e cidade nos discursos literários, Raymond Willians (1989) afirma que elas são feitas por meio de uma relação de oposição, e de uma forma semelhante acontece com seus habitantes, ou seja, a imagem do homem do campo atrasado era construída em oposição ao homem urbano moderno.

Se os discursos literários contribuíram para a construção de um conceito oposto entre homem do campo e homem da cidade, é possível identificar que o Almanaque do Biotônico Fontoura contribuiu para criar um estereótipo do sertanejo. Vejamos: 


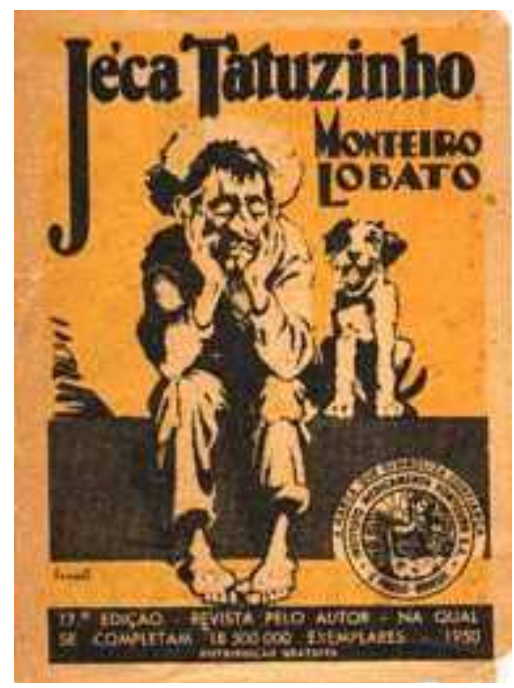

Figura 1: Capa do Folheto Jeca Tatuzinho

Fonte: Almanaque do Biotônico Fontoura (LOBATO, 1950)

Assim, no Almanaque Fontoura, logo na capa, o Jeca Tatuzinho aparece sentado, pés descalços, cotovelos apoiados nos joelhos e as mãos servindo de suporte para o rosto, este com aspecto cansado, a cabeça inclinada para baixo, evidenciando um desânimo profundo, e os olhos fechados não oferecem ações que o levem a uma perspectiva de olhar e tão pouco ânimo para abri-los e arriscar uma olhadela. Roupas velhas, remendadas, barras dobradas até o meio da canela, destacando a fragilidade dos ossos e a fisiologia desnutrida da pele. Na cabeça, um chapéu de palha, velho, de abas desfiadas, que mal dá conta de tampar o couro cabeludo. Atrás da orelha, um cigarro de palha que parece esquecido pelo próprio dono. Ao seu lado, de companhia, apenas um cachorro, provavelmente, o fiel companheiro, também sentado, contudo seu aspecto físico parece mais forte que o do Jeca. Com a cabeça levemente inclinada para cima, mesmo de olhos fechados, transmite a sensação de uma perspectiva de olhar. Neste sentido, se ambos abrissem os olhos, o primeiro avistaria a terra improdutiva que lhe rodeia os pés e o segundo, a amplidão do horizonte. Mas, independente da perspectiva, os dois estão cercados por um campo vazio e de coloração amarela, que acentua, aos olhos de quem vê a cena, a sensação de abandono, desânimo, miséria e falta de higiene.

Essa imagem visual do Jeca Tatu adentrou lares e escola, percorreu o espaço urbano e rural de diferentes regiões brasileiras e permaneceu no imaginário coletivo de várias gerações. E, embora, não fosse intenção de seus criadores, o Almanaque produziu uma representação do homem do campo como aquele que vivia na fronteira das ideias progressistas, contribuindo para cristalizar uma imagem representativa do sertanejo como homem atrasado e alheio à modernização.

\section{Referências}

ADLER, Richard P.; FIRESTONE, Charles M. A conquista da atenção: a publicidade e as novas formas de comunicação. São Paulo: Nobel, 2003.

CALVINO, Ítalo. Seis propostas para o próximo milênio. São Paulo: Companhia das Letras, 1995.

CARRASCOZA, J. A. Redação publicitária. 3. ed. São Paulo: Futura, 2004. 
CARVALHO, Marta Maria Chagas de. A escola e a república e outros ensaios. Bragança Paulista: EDUSF, 2003.

CHARTIER, Roger. A ordem dos livros: leitores, autores e bibliotecas na Europa entre os séculos XIV e XVIII. Brasília, DF: Ed. UnB, 1994.

COSTA, Cruz. Contribuição à história das idéias no Brasil. Rio de Janeiro: Civilização Brasileira S.A., 1967.

DIAS, Eliane Penha Mergulhão. A evolução da propaganda brasileira e a ideologia de orientação capitalista: uma relação dialética. GT - 02 - História da Publicidade e Propaganda UFSC, 2006. Disponível em: <http://www.redealcar. jornalismo.ufsc.br>. Acesso em: 11 maio 2010.

FOUCAULT, Michel. A ordem do discurso. São Paulo: Loyola Educação Brasil, 1999.

LEITE, S. C. Escola rural: urbanização e políticas públicas educacionais. 2. ed. São Paulo: Cortez, 2002.

LOBATO, Monteiro. Almanaque do Biotônico (Fontoura). São Paulo: Instituto Medicamenta, 1950. Ilustrado. 32pp. Dimensões de 13,5 x 18,5 cm. Variedades. Propagandas de Medicamentos.

MERISSE, A.; JUSTO, J. S.; ROCHA, L. C.; VASCONCELOS, M. S. Lugares da Infância: reflexões sobre a criança na fábrica, creche e orfanato. São Paulo: Artes \& Ciências, 1987.

NOVA, Vera Casa. Lições de Almanaque: um estudo semiótico. Belo Horizonte: Editora UFMG, 1996.

NUNES, Cassiano. Monteiro Lobato e Anísio Teixeira: o sonho da educação no Brasil. São Paulo: [s.n.], 1986.

PARK, Margareth Brandini. Histórias e leituras de almanaques no Brasil. Campinas: Mercado das Letras S/A FADESP, 1998.

. De Jeca Tatu a Zé Brasil: a possível cura da raça brasileira. Revista Sociedade e Agricultura, Rio de Janeiro: CPDA/UFRJ, v. 13, p. 143-150, out. 1999. Disponível em: <http://bibliotecavirtual.clacso.org.ar/ar/libros/brasil/cpda/ estudos/treze/park13.htm>. Acesso em: 22 ago. 2009.

ROSSI, Ednéia Regina. "Insuladas tribos". A escola primária e a forma de socialização escolar: São Paulo (1912-1920). Assis: Tese doutorado.2003.

SCHRAIBER, Lilia Blima. Educação médica e capitalismo. São Paulo: Hucitec/Abrasco, 1989. 
SEVCENKO, Nicolau. O prelúdio republicano, astúcias da ordem e ilusões do progresso. In: (Org.). História da vida privada no Brasil: República da Belle Époque à era do rádio. São Paulo: Companhia das Letras, 1998. v. 3 p. 7-47.

STEPAN, Nancy. Gênese e evolução da ciência brasileira. Rio de Janeiro:

Artenova/Fundação Oswaldo Cruz, 1976.

WILLIAMS, Raymond. O campo e a cidade: na história e na literatura. São Paulo: Companhia das Letras, 1989.

i A Associação Brasileira de Educação (ABE) foi criada em 1924 e tinha como foco a divulgação e legitimação dos ideais de uma educação renovada.

Recebido em: $\quad$ 12/12/11

Aprovado em: $\quad$ 20/02/12 